\title{
THE ENERGY EXCHANGE IN OBESITY
}

\author{
By JAMES M. STRANG, AND FRANK A. EVANS \\ (From the Medical Service of the Western Pennsylvania Hospital, Pittsburgh, Pennsylvania)
}

(Received for publication July 23,1928 )

The problem of obesity, in its many aspects, has been receiving attention in recent years and is becoming important in clinical practice. There are many points needing further examination. The popular prejudice, that fat people are frequently "small eaters" and, therefore, have some mystic power of handling food more economically than normal people, persists in spite of many reports demonstrating basal metabolic rates of the obese within normal limits. The fact that the fat person actually consumes more energy than he would if he were not obese has been emphasized by Labbé and Stèvenin (2) and by Lauter (3). Observations have been made repeatedly that the basal calories per day lie between 2000 and 2200 instead of the normal 1400 to 1600 . These data lend no support to the conception of a mysterious economy practised by the tissue infiltrated with fat. A long series of cases (1) successfully treated by dietary measures alone also questions the validity of this hypothesis. In this report, the evidence dealing with the caloric exchange of the obese in the basal state is reëxamined and correlated with additional data.

Basal heat production is customarily referred to the surface area of the body. The so-called basal metabolic rate expresses the per cent deviation of the basal calories per unit of body surface from the average values for normal persons. A review of the literature $(4,5,6$, $7,8,9)$ shows that the basal metabolic rates of obese persons fall within normal limits. Our observations are in accord with these data.

It is, therefore, established that a pudgy woman of forty-nine years, 5 feet tall, weighing 294 pounds has only 6 per cent less energy exchange in the resting state than a man of the same age, 6 feet 3 inches tall, weighing ideally 205 pounds. The surface is the same in the two cases, namely, 2.22 square meters. It is apparent, however, that there is a fundamental difference in the two cases. The measure of the 
physiological handicap in the obese might better be stated by comparing the metabolism of the obese woman, not with that of a normal person having the same surface,- - a veritable giant-but with that of a person comparable to her in all respects other than weight and surface. Our basis of comparison is, therefore, the caloric requirements which she herself might have had if only she were of normal weight.

The data reported herein are in terms of the percentage of weight, surface, and calories-per-hour above the corresponding values for persons of the same age and height, but of ideal weight.

\section{METHODS}

The observations reported here were made on eight obese women normal except for their excess weight. They were being reduced by dietary measures alone over periods varying from a few days to twenty weeks. All of them were so

TABLE 1

Basal heat production in the obese

\begin{tabular}{|c|c|c|c|}
\hline & $\begin{array}{c}\text { Number of } \\
\text { cases }\end{array}$ & $\begin{array}{c}\text { Average } \\
\text { calories per } \\
\text { hour }\end{array}$ & $\begin{array}{l}\text { Average basal } \\
\text { metabolic rate }\end{array}$ \\
\hline & & & per cent \\
\hline Means $(4) \ldots \ldots \ldots \ldots$ & 10 & 81 & 0 \\
\hline Strouse and Wang (5). & 10 & 74 & +1 \\
\hline Present series $\ldots \ldots \ldots \ldots \ldots \ldots \ldots \ldots \ldots$ & 7 & 73 & -3 \\
\hline
\end{tabular}

intelligent and reliable that their adherence to the prescribed routine was not to be doubted. In this series, there were three completed cases, three only partly reduced and two cases which have been observed for less than one month. All of these patients carried on their usual activities throughout the dietary period.

The diet was calculated on the basis of 1 gram of protein and 25 calories per kilogram of ideal weight. Utilizing a FA/G ratio of 1.5, the grams of protein, carbohydrate, and fat were determined. From these figures, the menu was made up including the protein and carbohydrate and omitting as much of the fat as possible. This made possible diets with 600 to 650 calories total intake which was equivalent to 6 calories per kilogram actual weight in some of the patients studied.

Basal metabolism determinations were done at intervals varying from a few days to two weeks using standard technique. The Tissot apparatus was used and gas samples were analyzed in duplicate.

The current insurance tables were used as standards of ideal weight (16). Surface area was calculated from the Boothby-Sandiford logarithmic chart (17). A study of nitrogen balance in one patient of this series showed that the diet 
JAMES M. STRANG AND FRANK A. EVANS

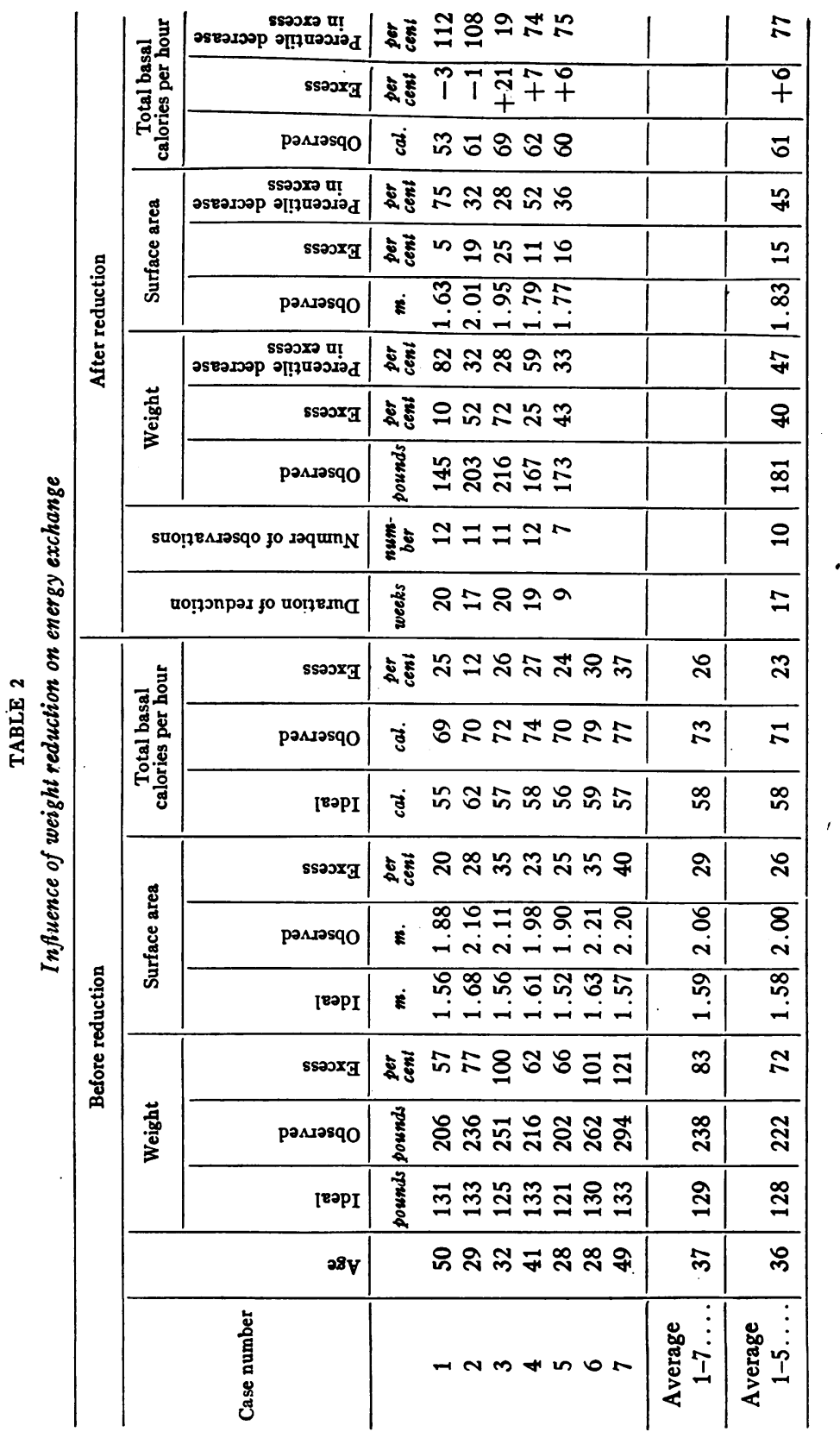


given kept her approximately in nitrogen equilibrium. This observation and investigations in another series of cases to be reported later give reason to believe that all the patients maintained an approximate nitrogen balance during the period of dieting.

\section{OBSERVATIONS}

The data presented are based upon 70 observations, 53 of which were made on the 5 cases which are considered as "reduced." The figures showing the status prior to dieting are the lowest values obtained before the diets began. There is no evidence that the determinations were in any way unusual.

A summary of our data appears in table 2. The averages of the initial data represent observations on all 7 cases. For comparison

TABLE 3

Influence of diet on calories per hour

\begin{tabular}{c|c|c|c|c|c|c}
\hline Case number & Outset & First month & $\begin{array}{c}\text { Second } \\
\text { month }\end{array}$ & Third month & $\begin{array}{c}\text { Fourth } \\
\text { month }\end{array}$ & Fifth month \\
\cline { 2 - 4 } & 69 & 65 & 63 & 62 & 53 & 52 \\
2 & 70 & 68 & 63 & 64 & 63 & \\
3 & 72 & 75 & 73 & 76 & 72 & 69 \\
4 & 74 & 69 & 64 & 65 & 62 & 62 \\
5 & 70 & 66 & 58 & 60 & & \\
\hline Average..... & 71 & 66 & 64 & 65 & 62 & 61 \\
\hline
\end{tabular}

with the figures after reduction, the averages of the initial values for the 5 reduced cases are tabulated separately. The influence of weight reduction is shown in the second part of the table. These figures describe the metabolic status of each patient on the day of her last examination after the designated period of dietary restriction.

The influence of dietary measures on the total calories per hour is indicated in table 3 which shows the average values for all determinations made during the given months.

Eight observations have been made upon a woman 52 years of age who was only 25 per cent overweight at the outset. Her surface was 11 per cent increased and the calories, 4 per cent above the ideal normal. In 6 weeks, she was reduced to 7 per cent excess weight with corresponding surface but no significant change in total 
calories. In view of the order of magnitude of the initial values, it was felt mathematically unjustifiable to include these findings in the general average of such a small series of cases. This case is, however, important in that, when placed upon a maintenance diet, her metabolism increased 10 per cent in two weeks with a continued loss of weight.

In summary, the averages of observations made are as follows: Seven patients 83 per cent overweight, who had surface areas 29 per cent increased, used 73 calories-per-hour or 26 per cent more than what would be normal for them, if they were of normal weight. Five of these patients after prolonged periods of dieting lost 47 per cent of their excess weight, showed a reduction of 45 per cent of their excess surface, and a 77 per cent reduction in their excess calories. It is worthy of emphasis that before dieting the increase in calories consumed is proportional to surface area increase rather than to weight increase; and that, after dieting, the reduction in excess calories is out of proportion to that of both weight and surface area. The rate of drop in basal calories is more than one and one-half times as great as the change in either weight or surface area. In one case, it was over 3 times as much.

Those cases, studied before institution of the diet, showed a sharp drop in energy exchange immediately after it was begun and before an important weight change could occur. 'There was also a rise in metabolism to the upper limits of normal in patients studied on a maintenance diet after the period of restriction. These changes may in part measure the energy requirements of handling different amounts of food. Additional data on this point will be reported later.

\section{Weight changes}

The range of weight loss of 29 to 61 pounds, an average of 41 pounds, demonstrates again that successful reduction can be accomplished by dietary measures alone. These figures correspond to an average reduction of 18 per cent of the initial weight with a minimum of 14 per cent and a maximum of 29 per cent. In developing our picture of the physiological status, we may restate these data as reductions averaging 47 per cent of the excess weight with the limiting values of 28 per cent and 82 per cent respectively. 
Relatively large weight changes amounting to 2 to 4 pounds a day are commonly met with in the obese. This phenomenon is apparently explained by the variable capacity of fat deposits for water storage, a conception which is supported by Lauter's (3) statement that the water content of human fat may vary from 8 to 70 per cent. These large water shifts give rise to a plateau-and-step type of weight curve during reduction which has been mentioned by Newburgh (4) and others and which we have repeatedly observed. We do not, however, feel that this factor materially influences our data.

That a loss of fat tissue rather than a shifting water balance is responsible for the observed weight change is suggested by the following calculation. "Gross" calories ingested are used instead of "net" calories in view of the relatively small energy fraction supplied by food. The average basal calories per hour (table 3 ) plus 20 per cent is used as a measure of the total energy requirement (Mason (7)). Following the suggestion of DuBois (9) after Bozenraad, we estimate that $75 \mathrm{kgm}$. of fatty tissue have $65 \mathrm{kgm}$. of fat or 87 per cent fat.

Basal calories per hour $=65$

Basal calories per 24 hours $=1,560$

Daily energy requirement - basal plus 20 per cent $=1870$ calories

Average calories in diet $=620$ $1870-620$ equals 1250 calories from fat

$1250 / 9.3$ equals 134 grams of fat equals $134 \times 75 / 65$ or 155 grams of fatty tissue perday

Average duration $=17$ weeks or 119 days $\frac{155 \times 119 \times 2.2}{1000}$ equals 40.6 pounds

Weight loss observed $=41$ pounds

On the basis indicated above, we have, therefore, accounted for nearly all of the gross observed weight loss.

\section{Surface changes}

The significance of numerical values for body surface and surface changes depends upon the reliability of the method of estimation. We have used tables based upon the DuBois formula which seems to be generally credited as the best available approximation even for the obese $(3,4,10)$. 
The initial average surface of 2.0 square meters (maximum 2.16; minimum 1.88) is reduced to 1.83 (maximum 2.01; minimum 1.63). This represents a surface change of 8.5 per cent. However, we may note that the initial surface is 26 per cent greater than the ideal, the final only 15 per cent greater, thus giving a drop of 45 per cent of the excess surface.

At this point, it may be mentioned that, although the surface area has decreased rapidly-approximately 0.01 square meter per week (100 square centimeters or the area of two playing cards)-we have not found necessary the methods for improving skin tone which have been so much emphasized by Frumusson (12).

We have noted above that, in the initial state, the increase in basal metabolism in the obese is of the same order of magnitude as the increase in surface. Table 2 shows, however, that there is a loss of 14 per cent basal calories accompanying a loss of but 8.5 per cent in surface. Or, we may say that the calories drop 77 per cent of the excess as the excess surface is reduced 45 per cent.

That this ratio of rate of change of calories to rate of change of surface is a property characteristic of the obese is suggested by a comparison with the studies of Benedict described below.

\section{Energy exchange before reduction}

Our figures for 7 cases with normal metabolic rates actually show an increase in calories of 26 per cent above normal for them if of ideal weight. A recalculation in this way by us of 10 cases reported by Strouse and Wang (5) shows an average increase of 25 per cent. We have used only their cases studied by the Tissot method omitting the patient under 16 years old, the patient with an acute infection, and the patient with thyrotoxicosis. A similar recomputation of the data published by Means (4) in 1916 gives an average increase of 30 per cent for 10 cases. Two patients under 16 years of age are omitted. In order to afford a fair comparison, we have entirely recast Means' data in accordance with our present standards for weight, surface, and basal calories.

It will be noted that the increase in the energy exchange is not proportional to the increase in weight but is of the same order of magnitude as the increase in surface. 


\section{Effect of weight reduction on energy exchange}

If an obese patient may have a basal caloric requirement 30 per cent in excess of normal, it becomes important to know what happens to this excess when the weight is reduced. If the basal calories do not change, the reduced.person will have a metabolism comparable to that of a seriously toxic thyroid patient. There is some evidence to indicate that the production of thyrotoxic symptoms by simple dietary reduction is not an impossibility (unpublished case).

In reviewing these data, the limits of normal variations in metabolism must be kept in mind. Harris and Benedict (13) published data in 1921 showing the extreme variations of metabolism in a given person.

TABLE 4

Excess of weight, surface and energy in the obese

\begin{tabular}{|c|c|c|c|c|c|c|c|c|c|c|c|}
\hline & \multirow{2}{*}{ 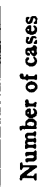 } & \multirow[b]{2}{*}{$\stackrel{\infty}{4}$} & \multicolumn{3}{|c|}{ Weight } & \multicolumn{3}{|c|}{ Surface } & \multicolumn{3}{|c|}{$\begin{array}{c}\text { Total basal } \\
\text { calories per hour }\end{array}$} \\
\hline & & & $\underset{\overparen{g}}{\overparen{\Xi}}$ & 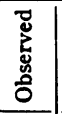 & 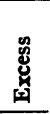 & 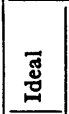 & 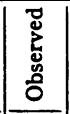 & $\begin{array}{l}\text { 怘 } \\
\text { 㟧 } \\
\end{array}$ & 苟 & 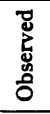 & 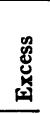 \\
\hline & . & & & & $\begin{array}{l}\text { per } \\
\text { cent }\end{array}$ & & & $\begin{array}{l}\text { per } \\
\text { cent }\end{array}$ & & & $\begin{array}{l}\text { per } \\
\text { cent }\end{array}$ \\
\hline Means......... & 10 & 37 & 140 & 253 & 80 & 1.69 & 2.17 & 28 & 62 & 81 & 30 \\
\hline Strouse and Wang....... & 10 & 27 & 125 & 207 & 66 & 1.57 & 1.95 & 24 & 59 & 74 & 25 \\
\hline Present series ......... & 7 & 37 & 129 & 238 & 83 & 1.59 & 2.06 & 29 & 58 & 73 & 26 \\
\hline
\end{tabular}

Over a period of two years, a 14 per cent variation might be noted. However, in a series of cases studied from one to three months, the coefficients of variation were around 4 per cent of the average metabolism. DuBois (9) thinks that the variations in metabolism are smaller than the possible errors of the determinations.

Acidosis causes an elevation in metabolism. Mason (7) and others have found no evidence of clinical acidosis after the first few days of diet restriction in spite of the presence of acetone bodies in the urine. This absence of clinical acidosis is in accord with our own experience.

The average of our 5 cases shows a diminution of basal energy requirements of 240 calories or 14 per cent of the initial value. Expressed in terms of the physiological status, these cases, which initially were metabolising 23 per cent in excess of normal, have 
reduced to but 6 per cent above ideal metabolism, although they remain some 40 per cent overweight. This is a reduction of 77 per cent of this excess metabolism.

These figures, well beyond the limits of normal variations and surely not influenced by acidosis, indicate that weight reduction by dietetic measures does not theoretically, at least, expose these patients to the

TABLE 5

Metabolism in various forms of undernutrition

\begin{tabular}{|c|c|c|c|c|c|c|c|c|c|c|}
\hline & Type & Subject & 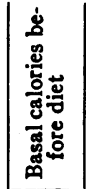 & 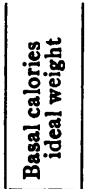 & 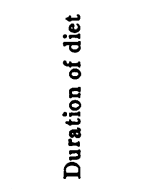 & 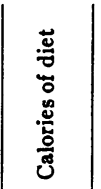 & 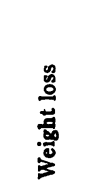 & 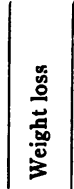 & 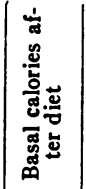 & 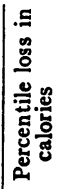 \\
\hline & & & & & & & $k g m$. & $\begin{array}{l}\text { per } \\
\text { cent }\end{array}$ & cal. & $\begin{array}{l}\text { per } \\
\text { cent }\end{array}$ \\
\hline $\mathbf{I}^{*}$ & Acute & Squad B & 1,745 & 1,745 & 3 weeks & $\begin{array}{c}1,375 \\
\text { net }\end{array}$ & 4.5 & 6.5 & 1,293 & 32 \\
\hline $\mathrm{II}^{*}$ & $\begin{array}{c}\text { Starva- } \\
\text { tion }\end{array}$ & Leveran. & 1,432 & 1,432 & 3 weeks & 0 & $10.1 \dagger$ & 17.0 & 1.002 & 30 \\
\hline III* $^{*}$ & Chronic & Squad A & 1,686 & 1,686 & 4 months & $\begin{array}{r}1,400 \\
(1,900 \\
\text { net })\end{array}$ & $\begin{array}{l}5.7 \\
\text { (Held } \\
\text { weight) }\end{array}$ & 8.5 & 1,367 & 19 \\
\hline IV & Obese & & 1,700 & 1,380 & 17. weeks & $\begin{array}{r}620 \\
\text { gross }\end{array}$ & 18.6 & 18.0 & 1,460 & 14 \\
\hline
\end{tabular}

* Essential data from Lusk (15) and DuBois (9).

† Estimated from graph.

danger of thyrotoxicosis. The energy exchange is diminished more than proportionally to the weight reduction.

In this connection, it may be stated that in no instance have the observed calories ever been lower than minus 5 per cent of the theoretically normal metabolism. Only 7 observations of less than the theoretical zero have been made in the entire series of 70 and 4 of these were made on patient number 1 toward the end of her reduction period when her weight was approaching the final 5 per cent above normal. This matter will be considered in detail in a later study. 
Can this conclusion in regard to weight reduction in the obese apply to loss of weight in a normal person? Is the physiological reaction the same? For answer one might refer to the well-known work on this question of Benedict (14) and his collaborators which is briefly summarized below. It is useful to distinguish three degrees of undernutrition, acute and chronic undernutrition, and starvation. For comparison with our data one example of each type is taken from Benedict. In tables 5 and 6, the figures for Squad A and B are taken from Lusk's (15) review of Benedict's work, and, in consequence, certain values differ very slightly from the original data of Benedict.

In comparing ours with those of Benedict, it must be emphasized that his cases were healthy active males while our patients were

TABLE 6

Rates of change of weight, surface and energy

\begin{tabular}{|c|c|c|c|c|c|c|c|}
\hline Group & Type & Subject & $\begin{array}{c}\text { I } \\
\text { Weight } \\
\text { loss }\end{array}$ & $\begin{array}{c}\text { II } \\
\text { Surface } \\
\text { loss }\end{array}$ & $\begin{array}{c}\text { III } \\
\text { Basal } \\
\text { calories } \\
\text { loss }\end{array}$ & $\begin{array}{c}\text { IV } \\
\text { Ratio } \\
\text { Calorie loss } \\
\text { Weight loss }\end{array}$ & $\begin{array}{c}\mathrm{V} \\
\text { Ratio } \\
\text { Calorie loss } \\
\text { Surface loss }\end{array}$ \\
\hline & & & per cent & per cent & per cent & & \\
\hline I & Acute & Squad B & 6.5 & $<1.0$ & 32.0 & 4.9 & $32.0+$ \\
\hline II & Starvation & Leveran & 17.0 & 5.0 & 30.0 & 1.7 & 6.0 \\
\hline III & Chronic & Squad A & 8.5 & 3.3 & 19.0 & 2.2 & 5.9 \\
\hline IV & Obese & & 18.0 & 8.5 & 14.0 & 0.77 & 1.6 \\
\hline
\end{tabular}

obese females. They had at the outset physiologically normal basal metabolism, while that of this series was elevated 23 per cent.

In regard to weight loss, none of the undernutrition cases approaches the magnitude of loss of our patients. On a percentage basis, the starvation case lost a comparable amount.

Clinically, the response in the two groups was entirely different, the undernourished groups became less ambitious, less energetic, tried to conserve all possible energy. They were depressed, irritable, and unstable. In contrast to this, the obese cases showed consistently more initiative, had a desire to do things, and felt in all respects better than for years previously.

The physiological reaction is different in the different groups of cases. The first two dropped 30 per cent of their calories in three 
weeks. The third group dropped 19 per cent in approximately the time in which our obese patients reduced their energy exchange only 14 per cent. This disparity is given more significance when it is recalled that the energy drop in the first three groups represents a lowering of the ideal basal metabolic level, whereas the 14 per cent depression in Group IV corresponds rather to a 77 per cent return of an excessive metabolism toward normal. This difference is emphasized further when we note the marked disparity in diets. Group $\mathbf{I}$, on a diet 6 per cent greater than the basal needs, had a depression of 32 per cent in calories and a small loss of weight. Group II, at the time of the lowest metabolism, had a 30 per cent drop in calories while the weight loss was about one-half that of our patients. Group III, after the initial weight loss, was holding weight on a diet 42 per cent above the basal needs while the drop in calories was only 19 per cent of the initial value. In our obese patients, however, on a diet 57 per cent less than the basal needs, the initial metabolism was depressed only 14 per cent and the patients lost weight consistently.

These differences between the "undernutrition" groups and the "obese" group may be restated with different emphasis. If we compare the rate of loss of energy with rate of weight loss (column 4, table 6) it is seen that the ratios of the first three groups are all more than twice that of the obese patients.

In drawing conclusions regarding surface changes from the comparisons in table 6, caution is necessary in view of the possible errors in our recalculation from the figures in Lusk's (15) monograph. The figures for surface are based on the data for total calories and calories per square meter and should give an approximate notion of the surface change. Two suggestive observations may be mentioned: 1 , In the obese, the surface area changes more rapidly in proportion to weight change than in the normal of undernourished; 2 , the ratio of rate of change of calories to rate of change of surface (column 5 , table 6 ) is several times as great in the undernourished as in the obese.

These observations permit the conclusion that the physiological reaction in the obese to reduction by diet differs markedly from that in a patient of normal weight. In the latter type of patient, there is a severe depression of energy exchange, even though he started at normal levels. In the obese, this depression of energy exchange is 
very much less in proportion tolimitation of diet and weight loss and is only a return toward normal, never beyond, of an initially elevated rate. These observations, and the clinical differences in the two groups of cases, permit the conclusion that our patients were not physiologically undernourished. The obese, when on a limited diet-with sufficient protein-do not seem to require the protective depression of the energy exchange which Lusk describes in connection with the above groups of undernourished.

No difference in quality of reaction was noted in the response of the so-called "endocrine" obesity patients and the "over-eating" cases. There appears to be a difference in quantity of reaction due, perhaps, to the tendency of the former type to approach the theoretical basal metabolism more rapidly in proportion to weight loss than in the second type. The weight loss continues in all cases to be directly proportional to the degree of deficiency of exogenous calories.

\section{CONCLUSIONS}

1. The energy exchange in the obese, when compared to what would be normal for them, if on proper weight, is increased.

2. This increase in energy exchange is of the same magnitude as the surface area increase beyond that normal for them.

3. When obese patients are reduced by dietary measures alone, the energy exchange diminishes proportionally much more than the weight, or surface area.

4. In spite of this drop in basal calories the metabolism never goes below limits normal for proper weight.

5. This observation contrasts strikingly with the extreme energy economy in the individual of normal weight who is reducing by diet, as is shown by a comparison with Benedict's figures.

6. There is, therefore, no evidence of an energy economy in the obese.

\section{BIBLIOGRAPHY}

1. Evans, F. A., Proc. Am. Clim. and Clin. Assn., 1928. Treatment of Simple Obesity by Dietary Measures Alone.

2. Labbé, M., and Stèvenin, H., Compte Rendu Soc. de biol., 1923, lxxxviii, 9. Le metabolisme basal chezles obêses. 
3. Lauter, S., Klin. Wchnschr., 1926, v, 1696. Uber die Beziehungen zwischen Energiehaushalt, Wasserhaushalt und Gewicht bei Fettsucht.

4. Means, J. H., Arch. Int. Med., 1916, xvii, 704. Basal Metabolism in Obesity.

5. Strouse, S., and Wang, C. C., Arch. Int. Med., 1924, xxxiv, 275. Studies of Metabolism in Obesity. II. Basal Metabolism.

6. Preble, W. E., Bost. Med. and Surg. J., 1923, clxxxviii, 617. Obesity, Observations on 1000 Cases.

7. Mason, E. H., J. Clin. Invest., 1927, iv, 93. Studies upon Obesity: Source of Heat during Periods of Reduction.

8. Hagedorn, J. C., Holten, C., and Johansen, A. H., Arch. Int. Med., 1927, xl, 30. The Pathological Metabolism in Obesity.

9. DuBois, E. F., Lea \& Febiger, 1927. Basal Metabolism in Health and Disease.

10. VonGrafe, E., Ergebnisse der Physiol., 1923, xxi, Pt. II. Die Pathologische Physiologie des Gesamtstoff- und Kraftwechsels bei der Ernährung des Menschen.

11. Newburgh, L. H., Address before Penn. State Med. Soc., October, 1927.

12. Frumusson, J., William Wood \& Co., 1924. Cure of Obesity. Trans. from French.

13. Harris, J. A., and Benedict, F. G., J. Biol. Chem., 1921, xlvi, 257. Variation and Statistical Constants of Basal Metabolism in Man.

14. Benedict, F. G., Miles, W. R., Roth, P., and Smith, H. M., Carnegie Institution of Washington, Publication No. 280, 1919. Human Vitality and Efficiency Under Prolonged Restricted Diet.

15. Lusk, G., Physiol. Rev., 1921, i, 523. Physiological Effect of Undernutrition.

16. Foxworthy, F. W., C. V. Mosby Co., 1924. Life Insurance Examination.

17. Boothby, W. M., and Sandiford, R. B., Bost. Med. and Surg. J., 1921, clxxv, 337. Nomographic Charts for the Calculation of the Metabolic Rate by the Gasometer Method. 